\title{
Hyperhomocysteinemia and Ischemic Stroke: A Potential Dose-Response Association- A Systematic Review and Meta-analysis
}

\author{
Marte Holmen ${ }^{1}$ Anne-Mette Hvas ${ }^{1,2}$ Johan F. H. Arendt ${ }^{1}$ (1) \\ ${ }^{1}$ Department of Clinical Biochemistry, Aarhus University Hospital, \\ Address for correspondence Anne-Mette Hvas, PhD, Department of \\ Aarhus, Denmark \\ 2 Department of Clinical Medicine, Aarhus University, Aarhus, \\ Denmark \\ Clinical Biochemistry, Aarhus University Hospital and Department of \\ Clinical Medicine, Aarhus University, Palle Juul-Jensens Boulevard 99, \\ Aarhus North, DK-8200, Denmark \\ TH Open 2021;5:e420-e437. \\ (e-mail: anne-mette.hvas@clin.au.dk).
}

\section{Abstract}

Keywords

- stroke/prevention

- cerebrovascular disease

- homocysteine

- meta-analysis

Background and Purpose Previous studies suggest an association between increased homocysteine (Hcy) and risk of ischemic stroke. Yet, it remains unknown whether a dose-response association exists between Hcy levels and risk of ischemic stroke.

Methods Systematic literature searches were performed in PubMed, Embase, Scopus, and Web of Science. Inclusion criteria were studies investigating ischemic stroke risk in an adult population with measured Hcy levels. We computed odds ratios (ORs) for a $5 \mu \mathrm{mol} / \mathrm{L}$ increase in Hcy levels using a random effects meta-analysis.

Results In total, 108 studies met the inclusion criteria of which 22 were rated as highquality studies, and 20 studies included a dose-response analysis. Hcy levels were analyzed either as a continuous or categorical variable. The majority of the studies found an increased risk of ischemic stroke when comparing the highest-to-lowest Hcy strata. A graded association was observed over the Hcy strata, indicating a doseresponse association, with the most apparent effect when Hcy levels exceeded approximately $15 \mu \mathrm{mol} / \mathrm{L}$. No studies explored a potential nonlinear association between Hcy levels and ischemic stroke. Six studies were included in a meta-analysis, showing an OR of 1.43 (95\% confidence interval [Cl]: 1.28-1.61) per $5 \mu \mathrm{mol} / \mathrm{L}$ increase in Hcy levels.

Conclusion This review and meta-analysis indicate a dose-response association between Hcy levels and ischemic stroke. An evident increase in effect measures was observed when Hcy levels exceeded $15 \mu \mathrm{mol} / \mathrm{L}$, indicating a nonlinear association between ischemic stroke and Hcy levels. This nonlinear association warrants further study.

This study is registered with clinical trial (https://www.crd.york.ac.uk/prospero/; unique identifier: CRD42019130371).
\end{abstract}

\section{Introduction}

The comprehension that elevated homocysteine (Hcy) in plasma might predispose to arterial or venous throm-

received

May 7, 2021

accepted after revision

July 19, 2021
DOI https://doi.org/

10.1055/s-0041-1735978.

ISSN 2512-9465. boembolism emerged more than 40 years ago, when patients with homocysteinuria were observed to have a high risk of early vascular disease. ${ }^{1}$ This led to extensive research regarding the role of $\mathrm{Hcy}$ in cardiovascular

\section{(C) 2021. The Author(s).}

This is an open access article published by Thieme under the terms of the Creative Commons Attribution License, permitting unrestricted use, distribution, and reproduction so long as the original work is properly cited. (https://creativecommons.org/licenses/by/4.0/)

Georg Thieme Verlag KG, Rüdigerstraße 14, 70469 Stuttgart, Germany 
disease (CVD) and whether elevated Hcy is a modifiable risk factor.

Elevation of Hcy levels may be caused by several factors, including deficiency of vitamin B6, folate, and/or vitamin B12, due to insufficient intake or absorption, renal insufficiency, several drugs, ${ }^{2}$ lifestyle factors, such as smoking and alcohol intake, or genetic factors. ${ }^{3}$

Among fasting individuals, normal Hcy levels commonly range from 5 to $15 \mu \mathrm{mol} / \mathrm{L} .{ }^{4}$ Animal studies have demonstrated that elevated Hcy levels leads to complex changes within the blood vessel wall, with increased oxidative stress, proinflammatory effects, and endothelial dysfunction, indicating that an association between increased Hcy and CVD is biologically plausible. $^{5-7}$ Several studies have investigated the potential association between elevated Hcy concentration and risk of CVD, including stroke, but results are inconsistent. ${ }^{8-10}$

The Norwegian Vitamin Trial indicated that treatment with folic acid and vitamin B combination therapy effectively lowered Hcy levels by $28 \%$, but no effect was found on the incidence of ischemic stroke. ${ }^{11}$ The Vitamin Intervention for Stroke Prevention trail demonstrated similar results, with no significant reduction in the risk of stroke among patients treated with B-vitamin combinations. ${ }^{12}$ In contrast, the China Stroke Primary Prevention Trial reported a $24 \%$ risk reduction for ischemic stroke in the group that received folic acid treatment. ${ }^{13}$ While, a Cochrane review from 2017 found a small reduction in risk of stroke in patients treated with B12, folate and B6 vitamins compared with patients receiving placebo. $^{14}$

Systematic reviews of observational studies have reported a dose-response related association between Hcy levels and the risk of stroke, independent of other cardiovascular risk factors. ${ }^{15}$ The most recent literature investigating the doseresponse relationship between stroke and Hcy levels was performed in 2002; however, this review did not differentiate between ischemic stroke and hemorrhagic stroke. ${ }^{15}$ Therefore, we performed a systematic review and metaanalysis to assess the dose-response association between Hcy levels and the risk of ischemic stroke.

\section{Methods}

The present systematic review and meta-analysis was conducted in accordance with the Preferred Reporting Items for Systematic Reviews and Meta-Analyses (PRISMA) guidelines. ${ }^{16}$ The protocol was published in the Prospero database (ID: CRD42019130371).

\section{Literature Search}

Searches in PubMed, Embase, Scopus, and Web of Science were performed on May 8, 2020. Where possible, filters were applied to remove nonhuman studies, and non-English language publications. No limits were set with regard to publication year. Free-text and the Medical Subject Headings (MeSH) terms or Emtree-preferred terms were used. Search combinations included terms related to the following search categories: Hcy, thromboembolism, biomarker, and adult human population. The complete search combinations used in PubMed is provided hereinafter. Similar search combinations were used for searches in the remaining three databases.

\section{PubMed}

Search $((((()($ "Homocysteine”[Mesh] OR “Hyperhomocysteinemia"[Mesh] OR homocyst* OR hyperhomocyst*))) AND ((“Embolism and Thrombosis"[Mesh] OR "Myocardial Infarction"[Mesh] OR "Acute Coronary Syndrome"[Mesh] OR "Brain Ischemia"[Mesh] OR "Stroke"[Mesh] OR "Deep vein thrombosis" OR "pulmonary embolism" OR "lung embolism" OR thrombosis OR embolism OR thromboembolism OR stroke OR "acute stroke" OR "brain infarction" OR "cerebral infarction" OR "brain ischemia" OR "cerebral ischemia” OR "ischemic stroke" OR "intracranial embolism" OR "intracranial thrombosis" OR apoplexy OR "cerebrovascular accident" OR "cerebral stroke" OR "myocardial infarction" OR "myocardial infarct" OR "heart infarct" OR "heart infarction" OR "acute coronary syndrome" OR "acute myocardial infarction" OR "brain embolism” OR "cardiovascular stroke” OR "heart attack" OR "acute myocardial infarct" OR "acute heart infarction"))) AND ((“Biomarkers"[Mesh] OR "Blood"[Mesh] OR blood OR serum OR plasma OR biomarker OR "biological marker" OR "blood level" OR "blood levels"))) AND (("Humans"[Mesh] OR adult[MeSH Terms] OR adults[All Fields] OR adult[All Fields] OR patients[All Fields] OR patient[All Fields] OR humans[All Fields] OR human[All Fields]))) AND ((Danish[Language] OR Norwegian[Language] OR English[Language] OR swedish[Language])))) NOT ((comment[Publication Type] OR congress[Publication Type] OR letter[Publication Type] OR "Case Reports"[Publication Type])).

Initially, all thromboembolic events were included as outcome, as seen in our search combinations, resulting in a large number of eligible articles (-Fig. 1). Therefore, our inclusion/exclusion criteria were revised after screening of abstracts to include only articles with ischemic stroke as outcome for this review. This choice was based on results found in the 2017 Cochrane review ${ }^{14}$ which showed a potential association between Hcy and ischemic stroke in randomized trials of B-vitamin treatment.

Our inclusion criteria were studies investigating ischemic stroke events in patients with measured plasma Hcy providing original data on adult human populations. Both interventional and observational studies were included, including randomized trials, cohort, cross-sectional, and case-control studies. The accepted endpoint was acute ischemic stroke, including all subtypes. The exclusion criteria were as follows: nonoriginal literature, reviews, meta-analyses, guidelines, case studies, conference abstracts, and letters/editorials/ comments without original data; missing information on Hcy concentration or studies including hyper-Hcy as a binary variable; endpoint of transient cerebral ischemia and arteriosclerotic lesions without sign of thrombosis, and silent brain infarction; and language other than English.

First, 100 abstracts were randomly selected and screened independently by the three authors for either exclusion or inclusion to full-text screening. Any disagreement was solved by consensus. Screening of the remaining abstracts 


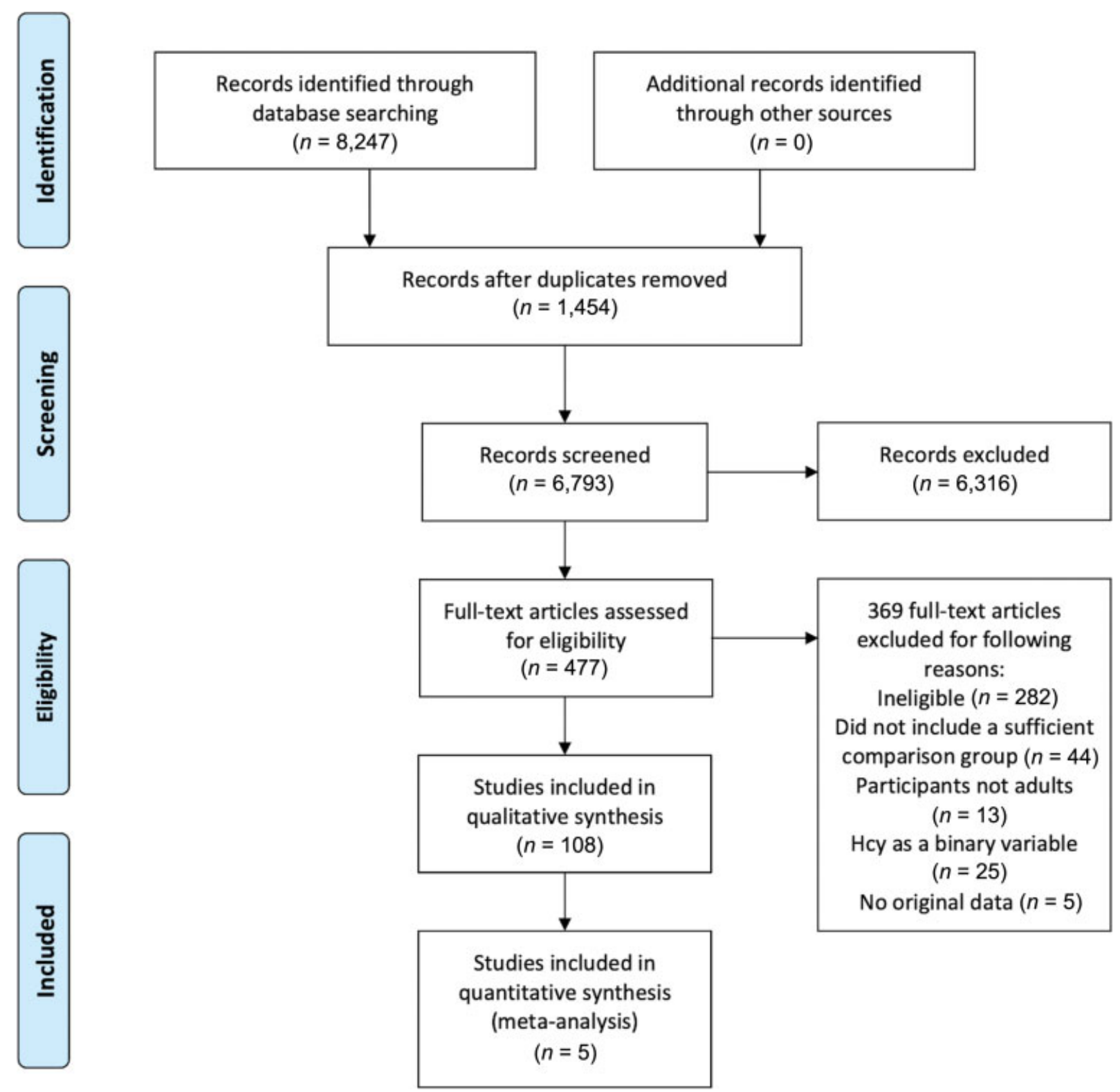

Fig. 1 Preferred Reporting Items for Systematic Reviews and Meta-Analyses (PRIMSA) flow diagram. ${ }^{16}$

was performed by $\mathrm{MH}$. Similarly, 50 randomly selected articles proceeding to full text screening were read in full by all authors, and any disagreement was solved by consensus. Remaining papers were screened by $\mathrm{MH}$ for inclusion or exclusion, and in case of doubt, all three authors discussed the study in question.

\section{Data Extraction and Quality Assessment}

Data extraction from the included articles was performed by M.H. and verified by A.M.H. and J.F.H.A. Study quality was assessed by all three authors using the Study Quality Assessment Tools for Observational Cohort and Cross-Sectional studies and for Case-Control studies, National Heart, Lung, and Blood Institute, National Institute of Health, the United States. ${ }^{17}$ Each study was rated good, fair or poor according to the estimated risk of bias. Disagreement between authors was solved by consensus.

\section{Data Synthesis}

We performed a meta-analysis of odds ratios (ORs) in which Hcy was included as a continuous linear variable. ${ }^{18-23}$ Hcy increments was standardized to $5 \mu \mathrm{mol} / \mathrm{L}$. A random effects model was used to obtain a summary OR as a measure of the relative risk. Forest plots and funnel plots were used to visualize the data.

\section{Results}

In total, 108 original articles were included in the review. Of these, 22 articles rated good, 47 fair and 39 poor. Screening of abstracts and inclusion of articles are shown in -Fig. 1. Articles rated good were grouped according to study design of which 18 were case-control studies and 4 were observational cohort studies, as presented in -Tables 1-3. Only articles rated good are reported on and discussed in this 
Hyperhomocysteinemia and Ischemic Stroke Holmen et al. e423

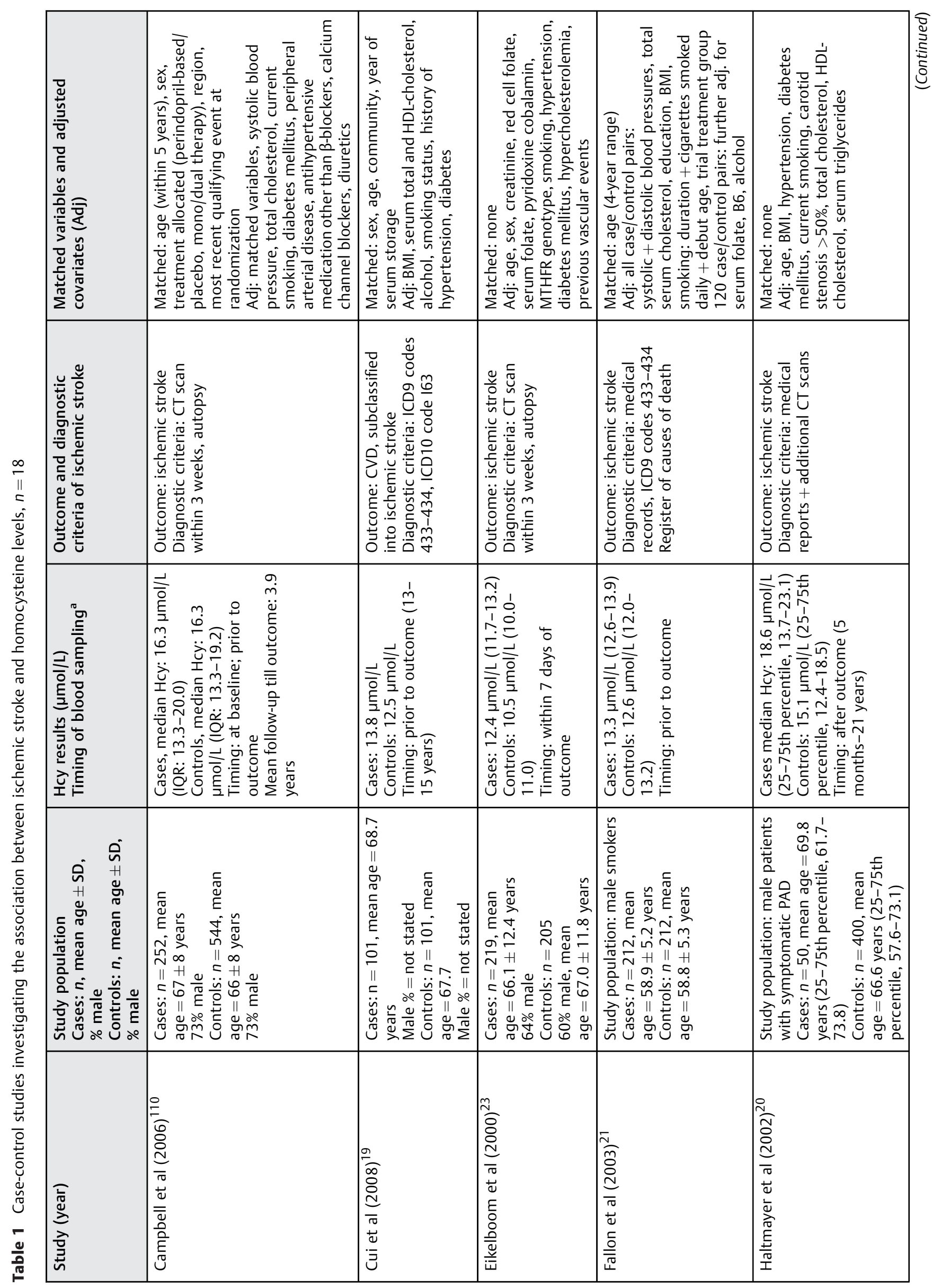




\begin{tabular}{|c|c|c|c|c|c|}
\hline 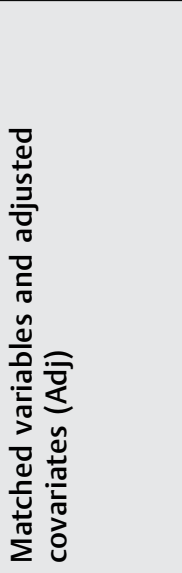 & 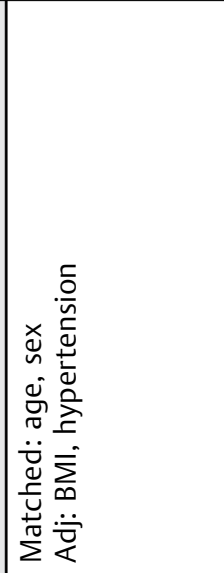 & 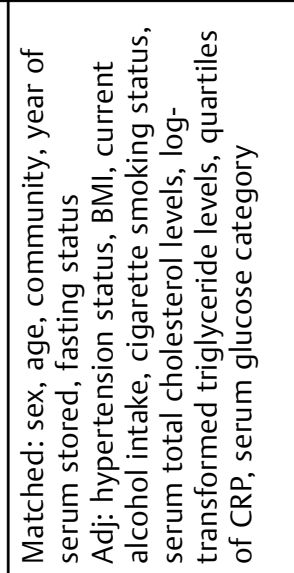 & 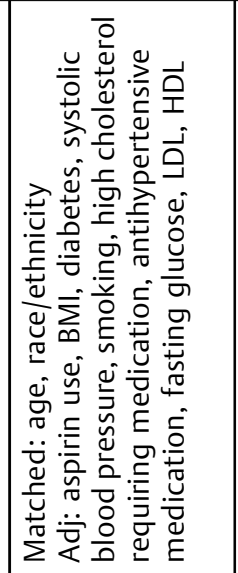 & 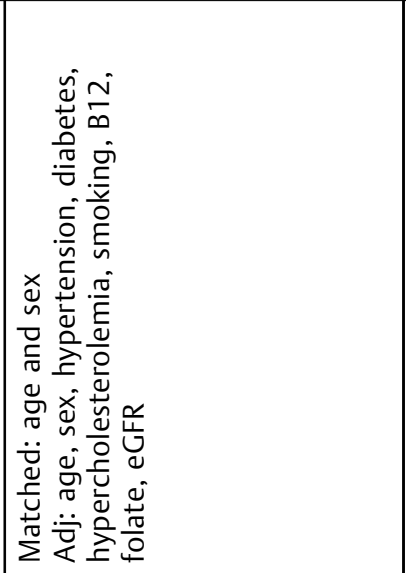 & 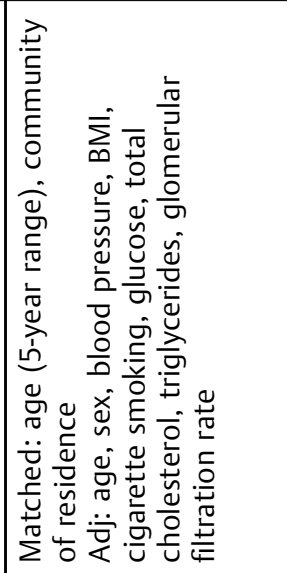 \\
\hline 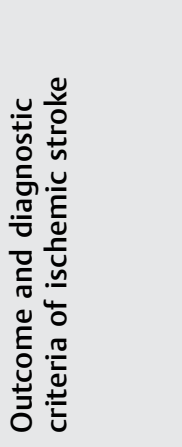 & 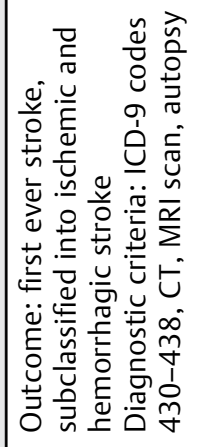 & 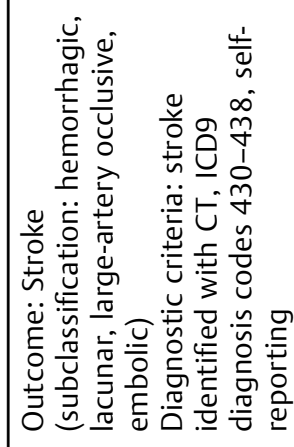 & 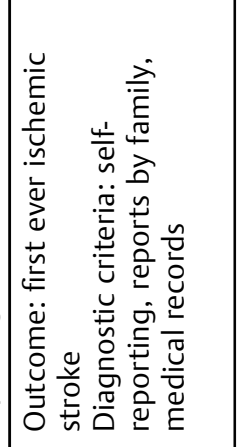 & 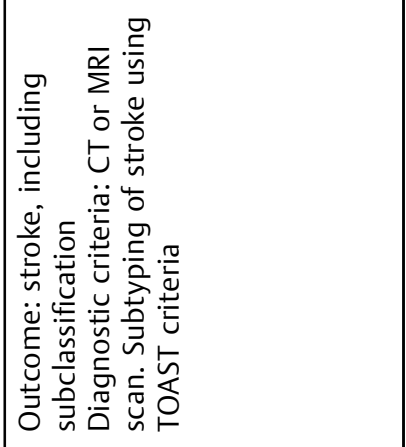 & 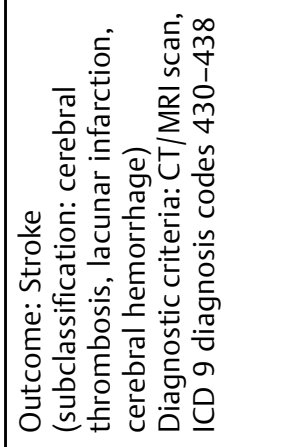 \\
\hline 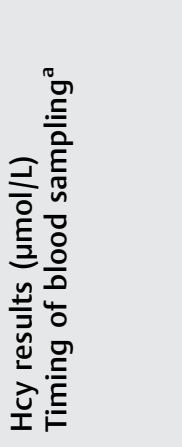 & 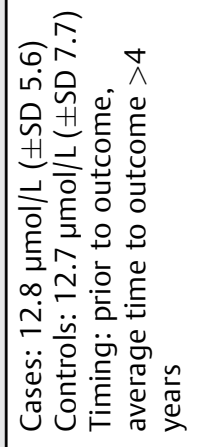 & 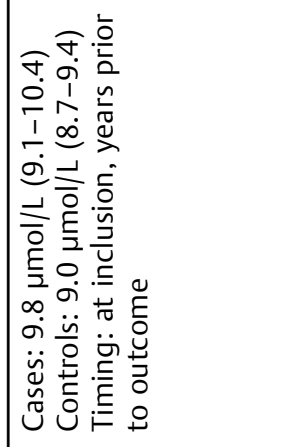 & 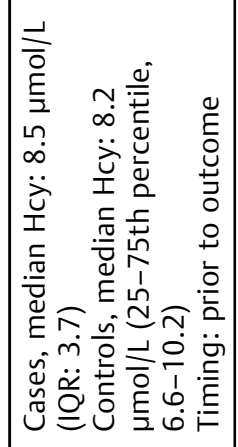 & 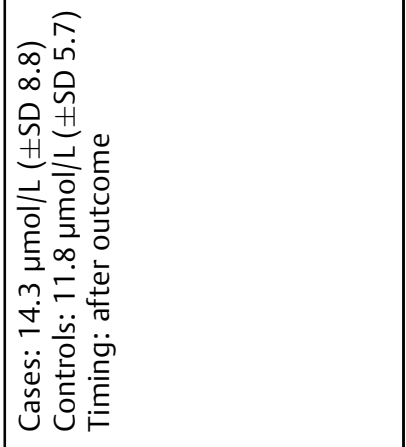 & 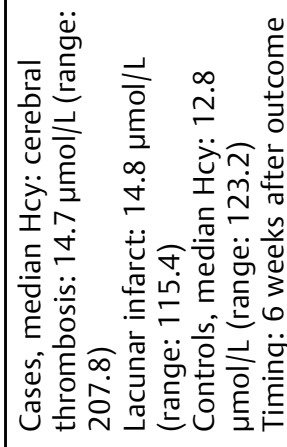 \\
\hline 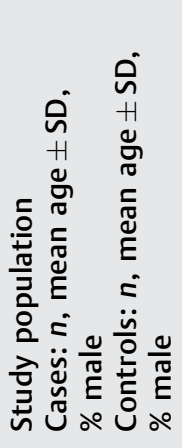 & 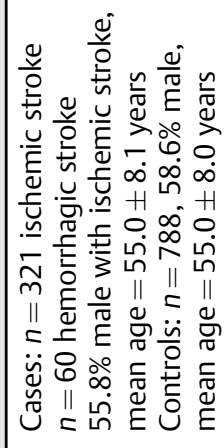 & 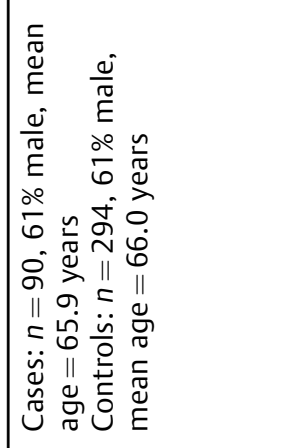 & 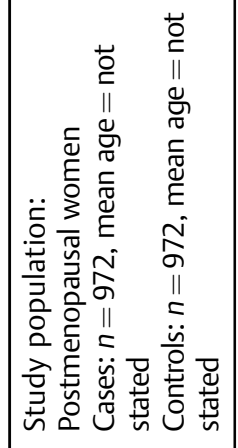 & 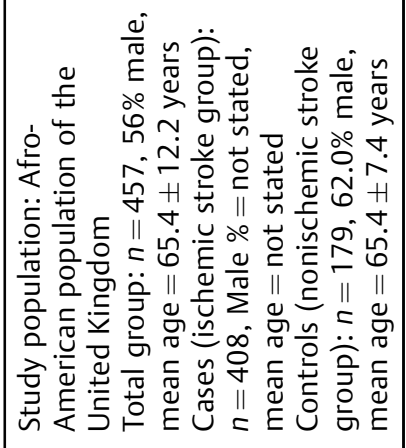 & 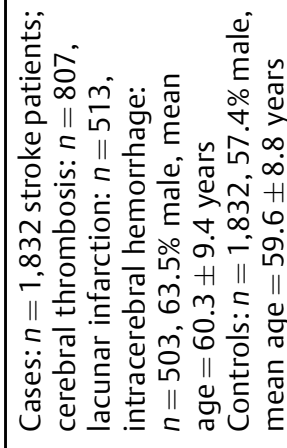 \\
\hline 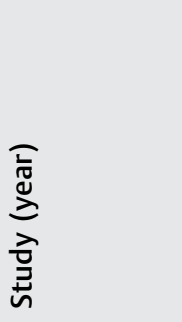 & 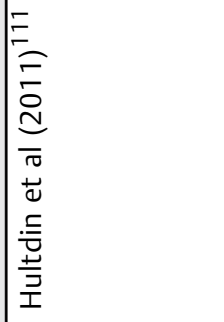 & 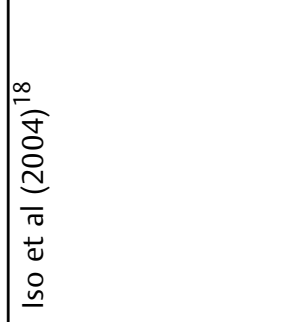 & 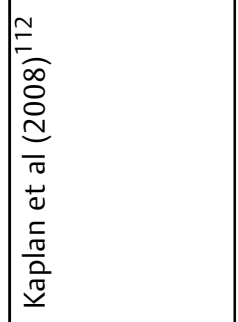 & 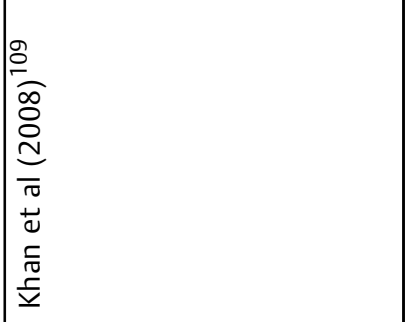 & 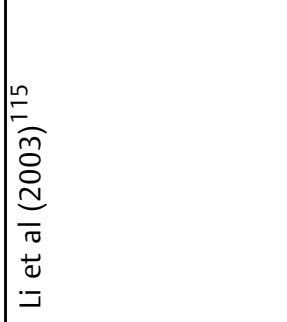 \\
\hline
\end{tabular}


Hyperhomocysteinemia and Ischemic Stroke Holmen et al. e425

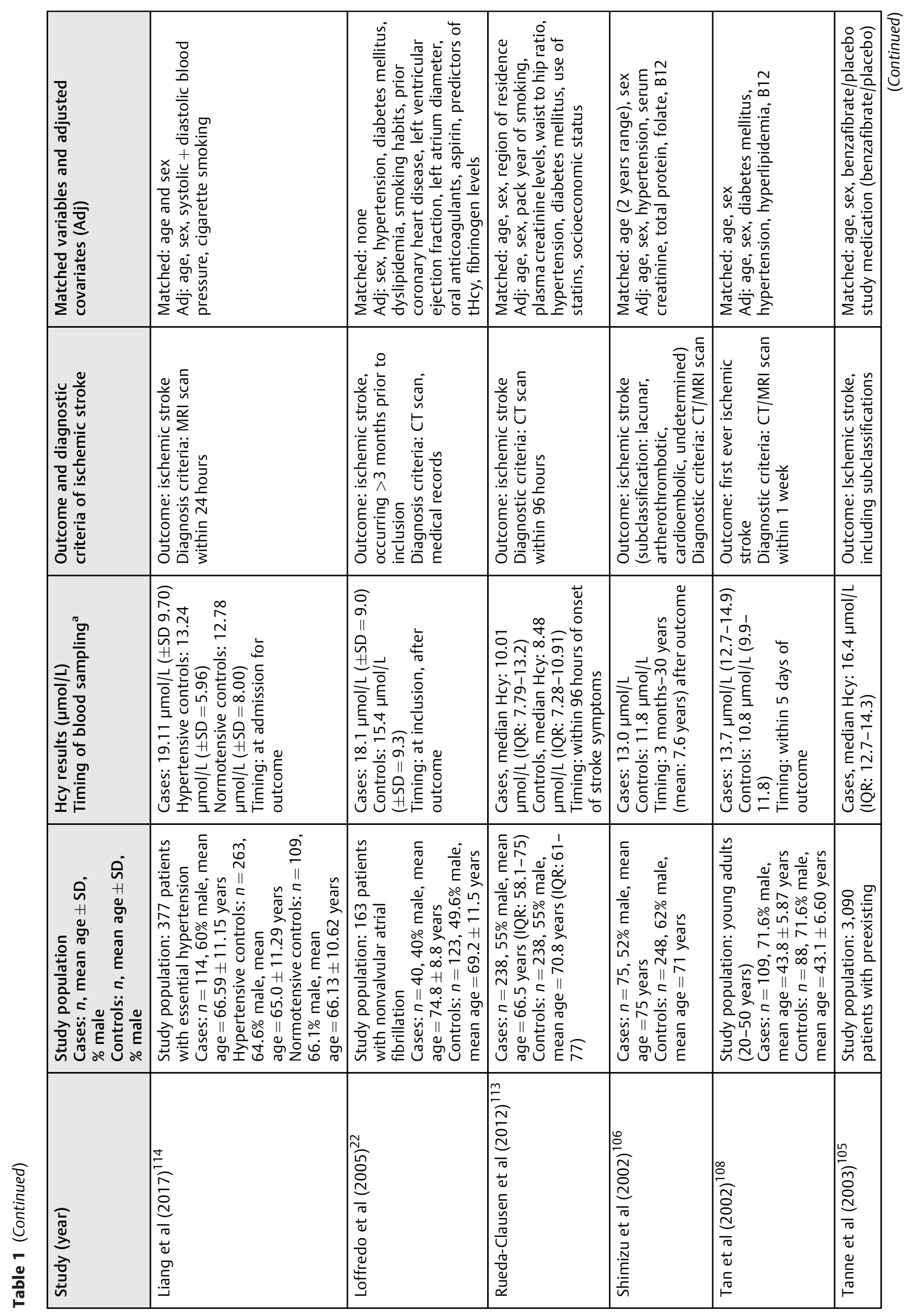




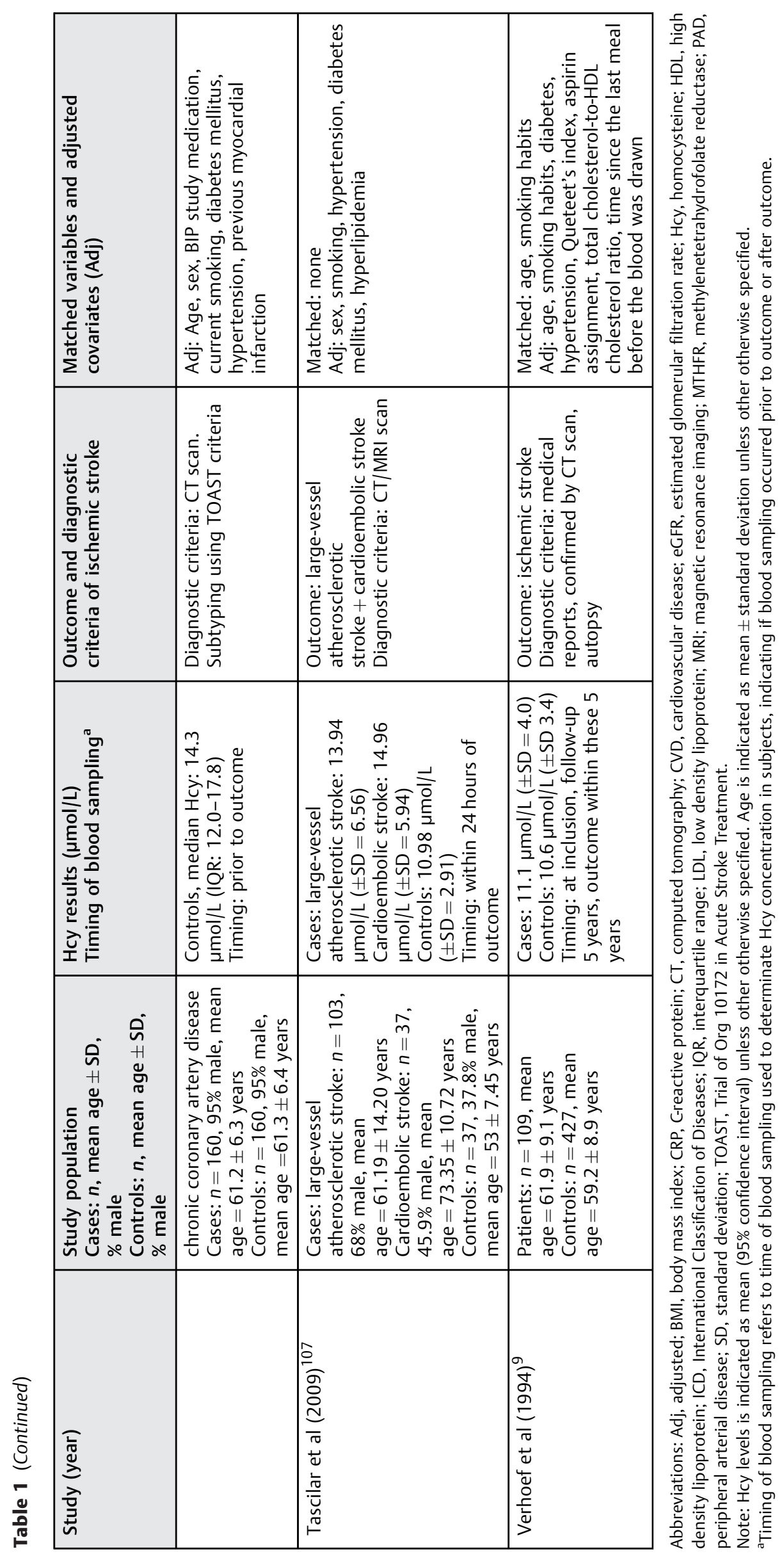


Hyperhomocysteinemia and Ischemic Stroke Holmen et al. e427

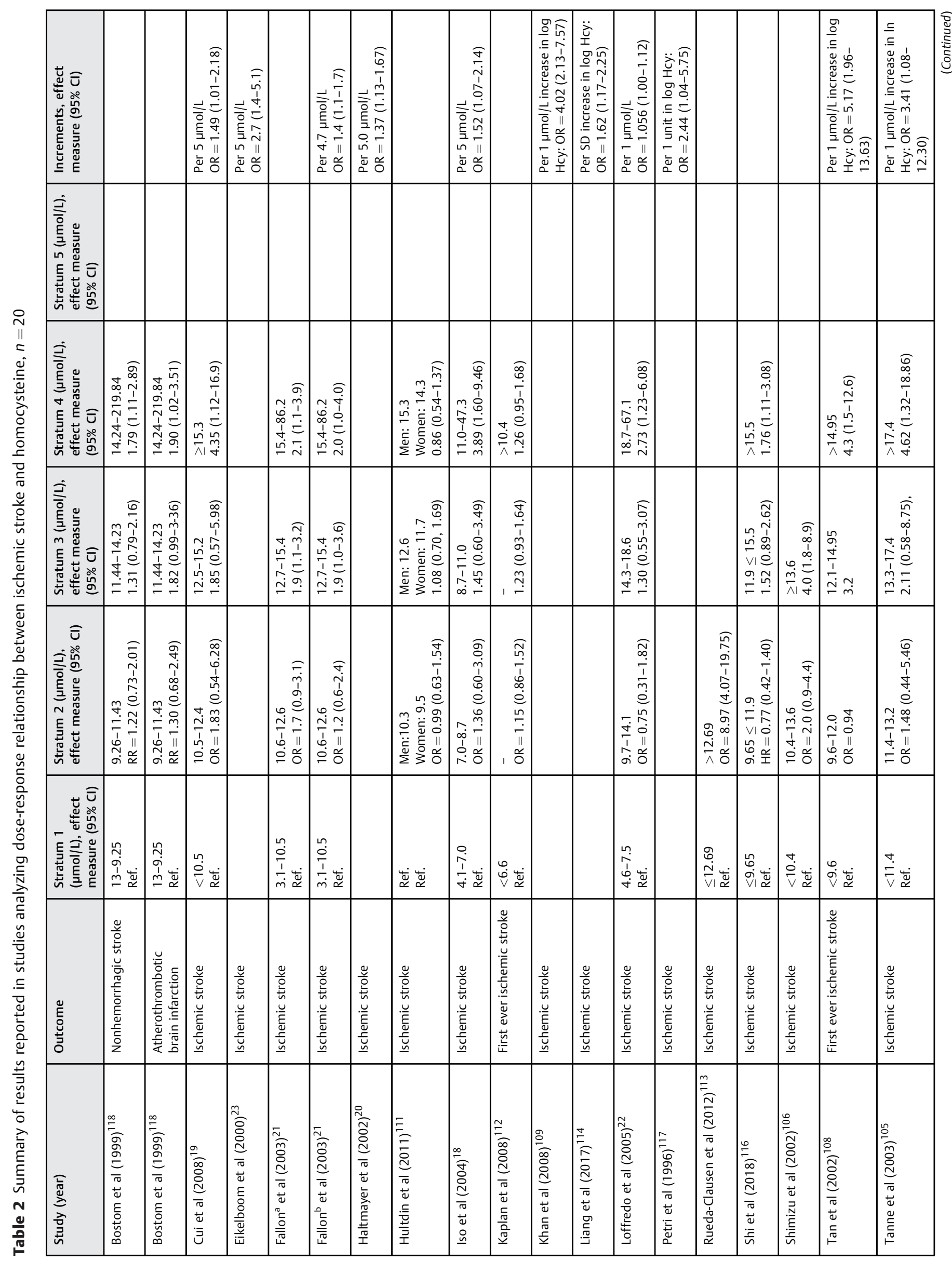




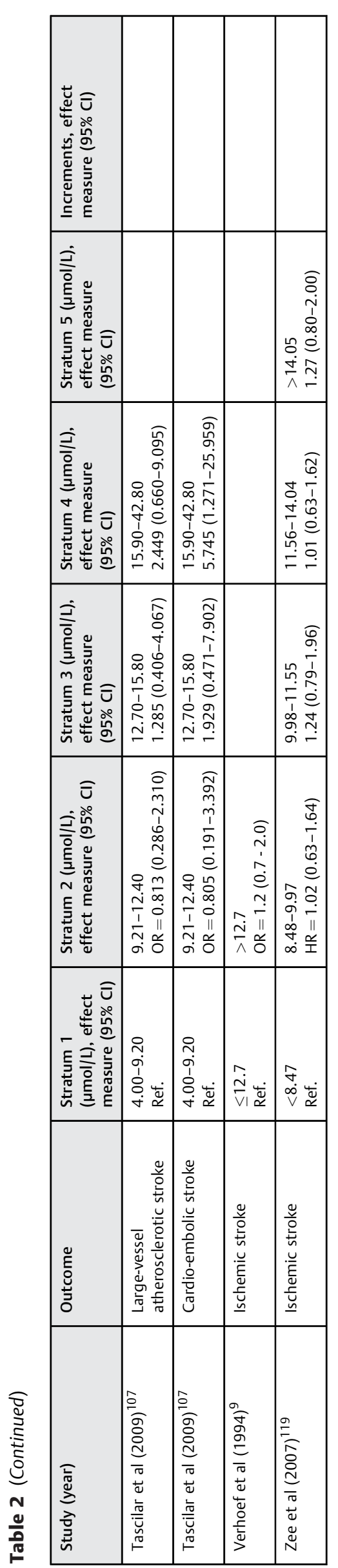

article. Studies rated fair ${ }^{24-68}$ and poor ${ }^{69-104}$ are provided in -Table 4. For the dose-response analysis, we included articles rated fair to supplement results in articles rated good (-Table 5).

\section{Case-Control Studies}

Of the 18 case-control articles rated as good, seven studies subclassified ischemic stroke ${ }^{18,105-109} ; 1$ reported CVD with subanalyses for ischemic stroke ${ }^{19}$ and 10 studies performed no subclassification of ischemic stroke. ${ }^{9,20-23,110-114}$

The timing of blood sampling for measurement of Hcy levels varied among studies. Eight studies performed blood sampling prior to outcome $e^{9,18,19,21,105,110-112} ; 10$ studies performed blood sampling after outcome, ${ }^{20,22,23,106-109,113-115}$ of which four studies collected blood within 7 days of outcome, ${ }^{23,108,113,114}$ and 2 studies within 24 hours of outcome. ${ }^{107,116}$

\section{Studies with Effect Measures Based on Homocysteine Strata}

Eleven studies stratified Hcy levels into several strata, estimating the risk of ischemic stroke in the lowest stratum compared with the higher strata ( - Table 2). ${ }^{18,19,21-23,105-108,111,112}$ Nine out of 11 studies found an increased risk of ischemic stroke when comparing patients in the highest versus lowest Hcy level strata. ${ }^{18,19,21-23,105-108}$ Two studies found no association between risk of ischemic stroke and Hcy level ${ }^{111,112}$ and one study reported an association for cardioembolic stroke, but not with large-vessel atherosclerotic stroke. ${ }^{107}$ Two studies estimated effect measures using a dichotomous Hcy; one study found an association, ${ }^{113}$ whereas one did not. ${ }^{9}$

\section{Studies with Effect Measures Based Homocysteine Increments}

Ten studies included Hcy as a continuous variable and presented effect measures based on various increments of Hcy (- Table 2). ${ }^{18-23,105,108,109,114}$ All studies found an association between increasing Hcy levels and odds of ischemic stroke, despite variations in the Hcy level increments that were employed.

Six studies included analysis of ischemic stroke subclasses. ${ }^{23,105-109}$ Among these, four studies showed an association between small-vessel disease and/or large-vessel disease, ${ }^{23,106,108,109}$ and three studies demonstrated an association with cardioembolic stroke. ${ }^{105,107,109}$

Two studies did not include effect measures illustrating the dose-response association between ischemic stroke and Hcy levels. ${ }^{110,115}$

Overall, in studies comparing Hcy strata, effect measures were clearly elevated when Hcy level reached $15 \mu \mathrm{mol} / \mathrm{L}$ and above (-Table 2).

\section{Cohort Studies}

Four cohort studies were rated as good, (-Table 3). ${ }^{116-119}$ Mean follow-up time ranged from 18 months to 9.9 years. Two studies included patients with CVD, with subanalyses for ischemic stroke. ${ }^{117,119}$ Zee et al did not find an association when comparing quintiles of Hcy levels in the population, ${ }^{119}$ whereas Petri et al found increased risk of ischemic stroke 

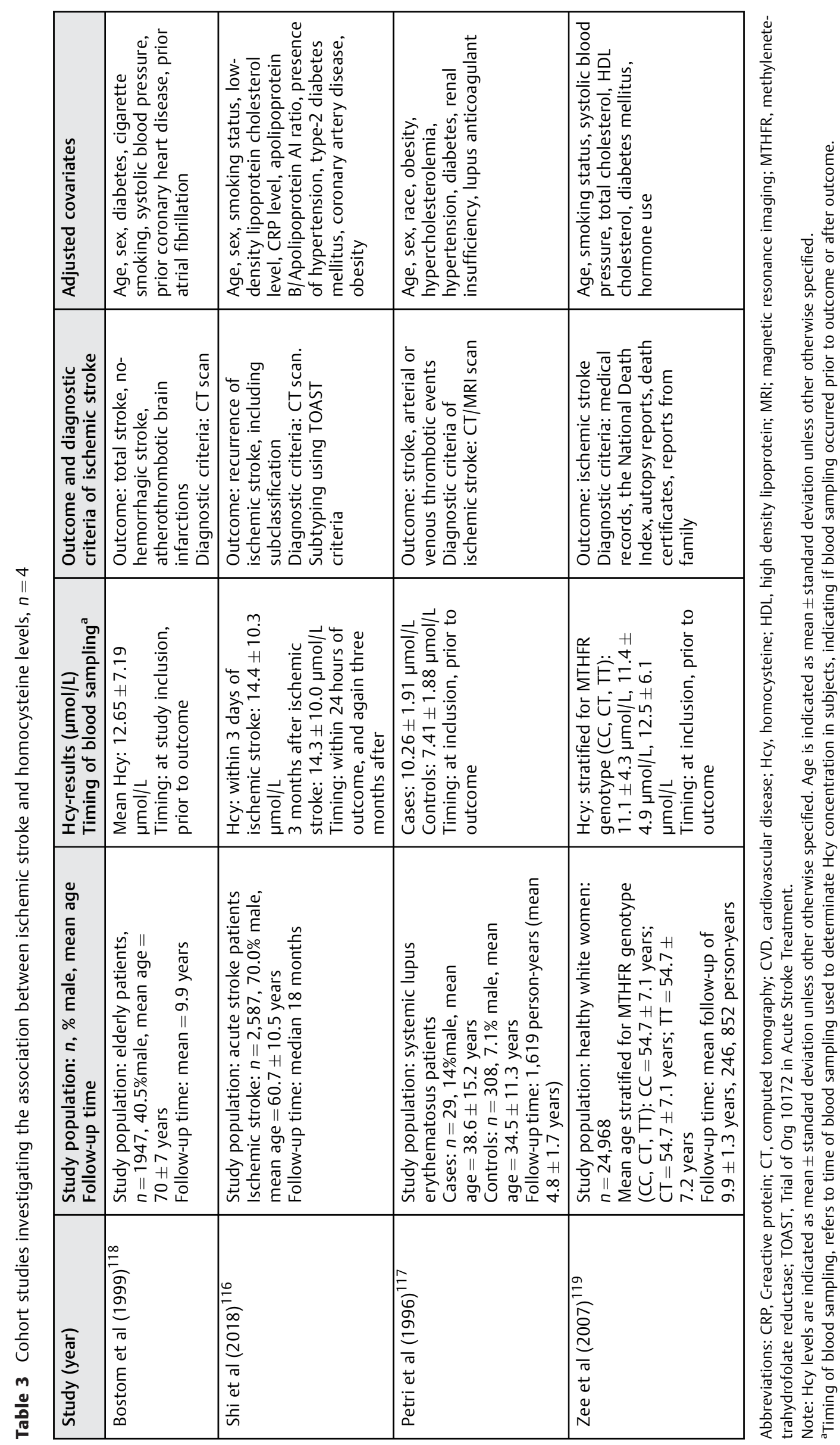
Table 4 Rating of individual studies that did not include a doseresponse analysis rated fair or poor

\begin{tabular}{|c|c|}
\hline $\begin{array}{l}\text { Study (year) } \\
\text { Rated fair }\end{array}$ & $\begin{array}{l}\text { Study (year) } \\
\text { Rated poor }\end{array}$ \\
\hline Case-control studies & Case-control studies \\
\hline Bosco et al $(2006)^{25}$ & Al-Allawi et al $(2009)^{71}$ \\
\hline Kelly et al $(2004)^{31}$ & Alkali et al (2006) \\
\hline Kim et al $(2011)^{32}$ & Araki et al $(1989)^{72}$ \\
\hline Kim et al $(2011)^{33}$ & Fekih-Mrissa et al (2013) \\
\hline Kristensen et al (1999) ${ }^{34}$ & Ma et al $(2017)^{42}$ \\
\hline Lee et al $(2008)^{36}$ & Sun et al $(2005)^{95}$ \\
\hline Li et al $(2018)^{38}$ & Tas et al $(2005)^{96}$ \\
\hline Lu et al $(2018)^{40}$ & Yi et al $(2013)^{101}$ \\
\hline Luo et al $(2017)^{41}$ & Yingdong et al (2002) \\
\hline Ma et al $(2011)^{43}$ & Cross-sectional studies \\
\hline Mao and Han $(2018)^{44}$ & Adunsky et al $(2000)^{69}$ \\
\hline Meiklejohn et al $(2001)^{45}$ & Ben-Salem et al $(2010)^{73}$ \\
\hline Modi et al $(2005)^{47}$ & Brattström et al (1992) \\
\hline Moe et al $(2008)^{48}$ & Cao et al (2019) ${ }^{128}$ \\
\hline Mojiminiyi et al $(2008)^{49}$ & Celikbilek et al $(2014)^{75}$ \\
\hline Pezzini et al $(2002)^{52}$ & Cingozbay et al (2002) \\
\hline Rahman et al $(2013)^{54}$ & Coull et al $(1990)^{77}$ \\
\hline Tantirittisak et al (2007) ${ }^{55}$ & $\begin{array}{l}\text { El Kossi and Zakhary } \\
(2000)^{78}\end{array}$ \\
\hline Vayá et al $(2011)^{57}$ & Fatima et al $(2012)^{79}$ \\
\hline Yang et al $(2004)^{62}$ & $\begin{array}{l}\text { Karakurum Goksel et al } \\
(2007)^{81}\end{array}$ \\
\hline Yang et al $(2016)^{63}$ & Han et al $(2002)^{82}$ \\
\hline Zhang et al (2014) & Karabulut et al $(2017)^{83}$ \\
\hline Zhang et al (2019) ${ }^{67}$ & Kokocińska et al (2005) \\
\hline Cohort studies & Li et al $(2004)^{85}$ \\
\hline Press et al (1999) ${ }^{53}$ & Liu et al $(2005)^{86}$ \\
\hline Cross-sectional studies & Moghaddasi et al $(2010)^{87}$ \\
\hline Dai et al $(2020)^{129}$ & $\begin{array}{l}\text { Mykhalojko and Mykhalojko } \\
(2017)^{88}\end{array}$ \\
\hline Haapaniemi et al $(2007)^{27}$ & Narang et al (2009) \\
\hline Kara et al $(2009)^{29}$ & Omrani et al $(2011)^{90}$ \\
\hline Kucukarabaci et al $(2008)^{35}$ & Peng et al $(2001)^{91}$ \\
\hline Lehmann et al $(2015)^{37}$ & Sawuła et al $2009^{92}$ \\
\hline Lindgren et al $(1995)^{39}$ & Sun et al $(2009)^{94}$ \\
\hline Mejia et al $(2011)^{46}$ & Sönmezler et al (2013) \\
\hline Ustundag et al $(2010)^{56}$ & Unal et al $(2013)^{97}$ \\
\hline Wei et al (2019) $)^{130}$ & Urbańska et al $(2006)^{98}$ \\
\hline Xia et al $(2014)^{60}$ & Wei et al $(2018)^{99}$ \\
\hline Yao et al $(2017)^{64}$ & Wu et al $(2017)^{100}$ \\
\hline \multirow[t]{2}{*}{ Zhu et al $(2013)^{68}$} & Zhang et al $(2014)^{103}$ \\
\hline & Zhou et al (2005) ${ }^{104}$ \\
\hline
\end{tabular}

with increasing Hcy levels. ${ }^{117}$ Bostom et al included elderly patients with stroke and found an association for both nonhemorrhagic stroke and atherothrombotic brain infarction, when comparing the highest quartile of Hcy to the lowest quartile. ${ }^{118}$ Shi et al investigated recurrence of ischemic stroke as outcome, with enrolment at admission for first ever stroke. Blood sampling was performed at 3 days and 3 months after enrollment. An association between the risk of recurrent ischemic stroke (within 12-36 months) and Hcy levels was found, when comparing the highest and lowest Hcy quartiles in blood samples performed 3 months after the enrollment. $^{116}$

\section{Meta-analysis of Dose-Response Association}

Eleven studies included Hcy as a continuous variable of which six were included in the meta-analysis. ${ }^{18-23}$ We normalized ORs to increments of $5 \mu \mathrm{mol} / \mathrm{L}$ in $\mathrm{Hcy}^{21,22}$ The remaining five studies performed log transformation of Hcy levels prior to statistical analysis and were therefore not included in the meta-analysis (- Table 2). ${ }^{106,108,109,114,117}$ The studies included in the meta-analysis reported similar results and included similar numbers of patients. All adjusted for age, sex, main CVD risk factors (diabetes, hypertension, hypercholesterolemia, smoking, and body mass index [BMI]), with an exception of Eikelboom et al that did not adjust for BMI. Eikelboom et al was the only study that adjusted for renal insufficiency ( - Tables 1 and 3). ${ }^{23}$ We performed a random effect analysis, resulting in an OR of 1.43 (95\% confidence interval [CI]: 1.28-1.61; $I^{2}=0.0 \%, p=0.492 ;$ - Fig. 2). A funnel plot for the metaanalysis is provided in - Fig. 3, as the resulting funnel plot was severely asymmetric.

Results reported in studies rated fair and further supported the observations reported in studies rated good (-Table 5).

\section{Discussion}

The present study indicates a dose-response association between Hcy levels and the risk of ischemic stroke. It was apparent that risk estimates reported in studies were notably higher when reaching Hcy levels above $15 \mu \mathrm{mol} / \mathrm{L}$, indicating a possible nonlinear association between Hcy and ischemic stroke. Both studies rated good and fair supported this observation.

Studies have shown that Hcy levels increase in patients within 1-week poststroke. ${ }^{27,39,45}$ This could explain some of the differences observed between cases and controls in the case-control studies where blood sampling was performed in cases during hospitalization for stroke. ${ }^{27,74}$ Moreover, Hcy levels have been shown to increase in critically ill patients. ${ }^{120}$ In this review, no difference in means was observed when comparing Hcy levels in blood samples obtained during the acute phases $23,107,108,114,116$ and convalescence phases of ischemic stroke $20,22,106,109$; but based on the aforementioned previous studies, timing of blood sampling should be considered when evaluating Hcy as an exposure.

Five studies showed an association between small- and large-vessel diseases when subclassifying stroke using the 


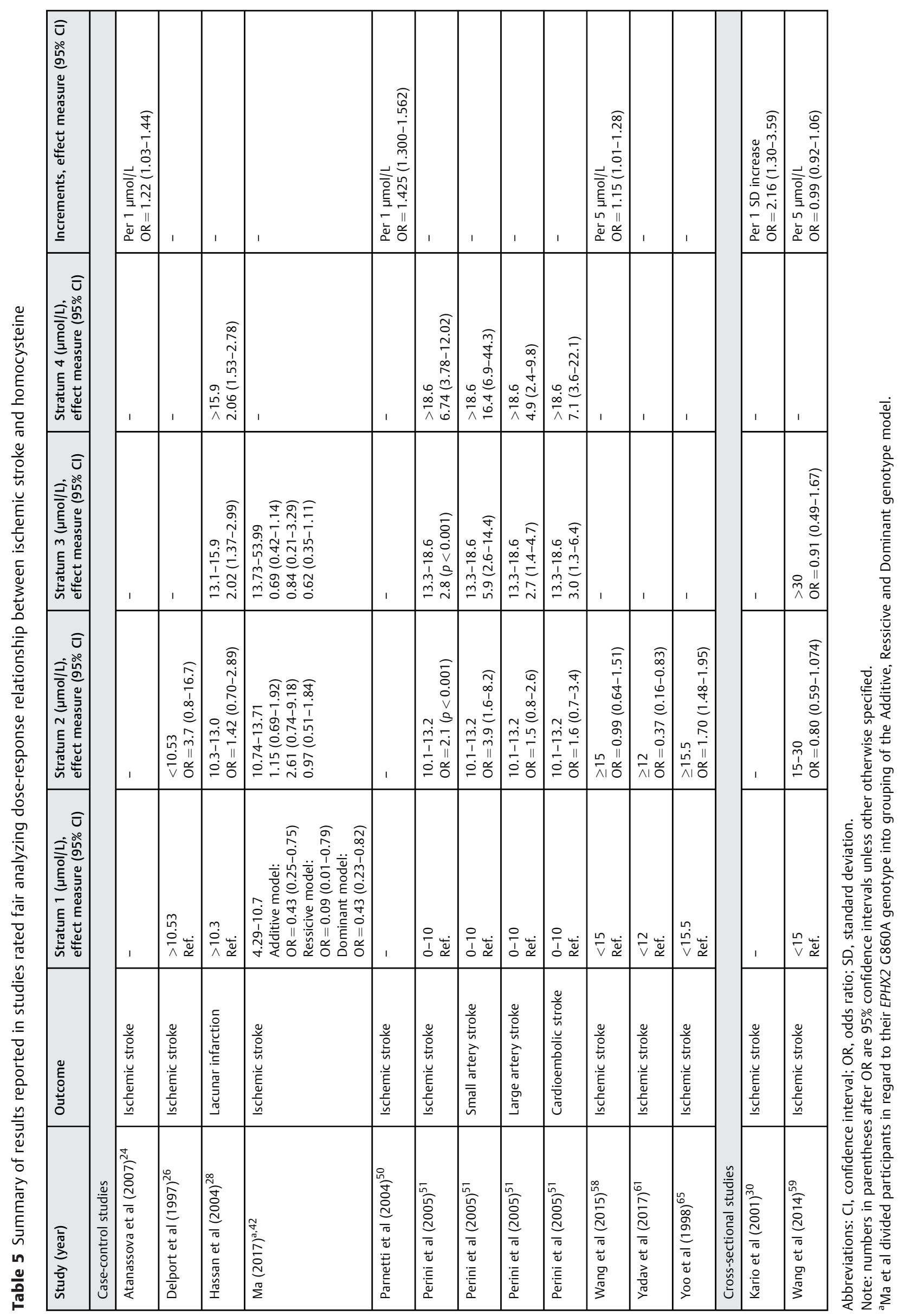




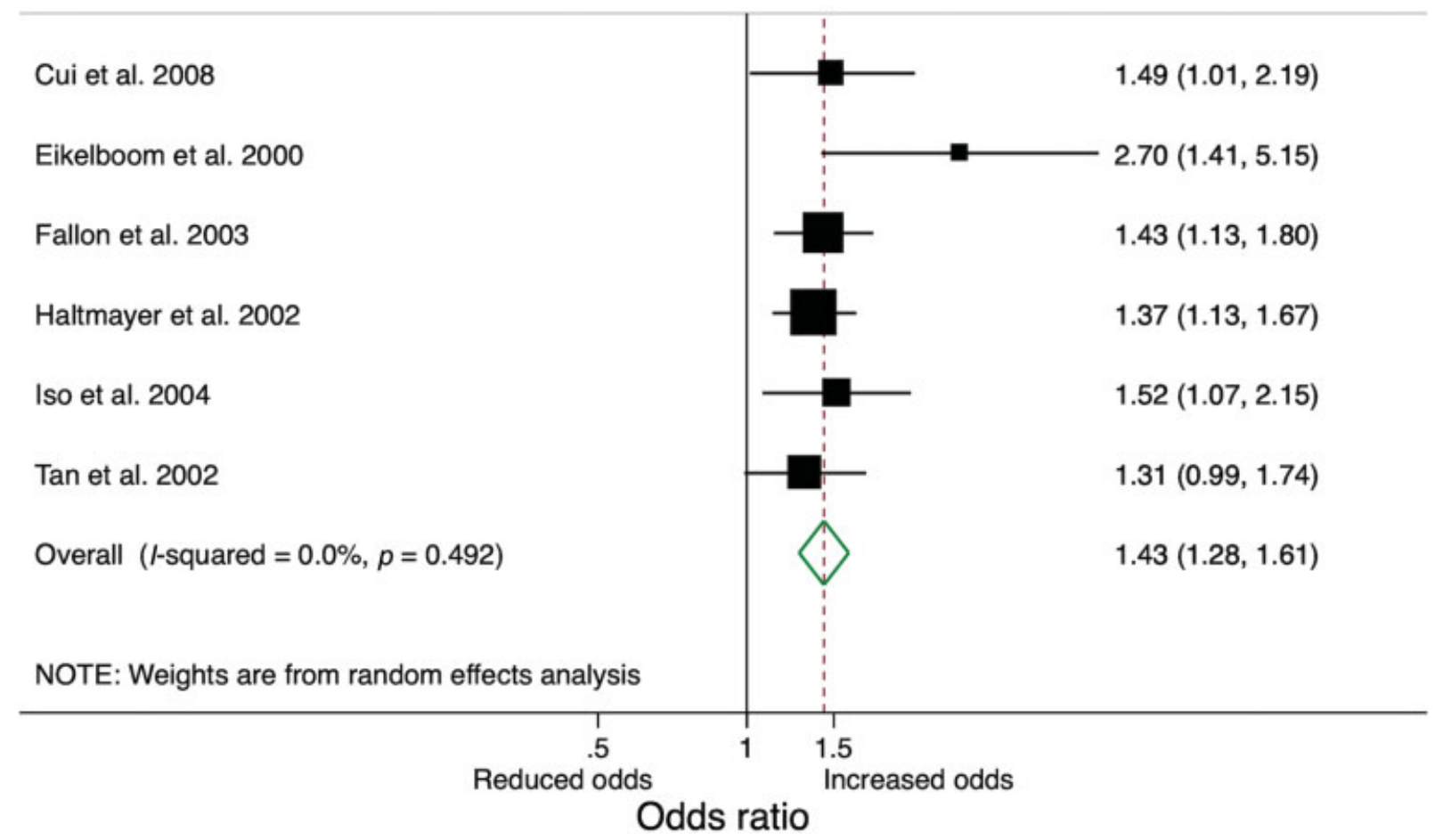

Fig. 2 Forest plot of risk of ischemic stroke per $5 \mu \mathrm{mol} / \mathrm{L}$ increase in plasma homocysteine. $\mathrm{Cl}$, confidence interval; OR, odds ratio.

Trial of Org 10172 in Acute Stroke Treatment (TOAST) criteria (-Tables 1 and 3). ${ }^{23,106,108,109,116}$ This finding indicates that the effect of Hcy could depend on the underlying etiologically of ischemic stroke. Large randomized controlled trails investigating the effect of Hcy-lowering B-vitamin treatment have not demonstrated an effect on vascular outcomes or stroke. ${ }^{11,12,121}$ Notably, reevaluation of data suggests that the effect of Hcy-lowering treatment could vary between outcomes, with a more beneficial effect on stroke than other CVD outcomes. ${ }^{14,122}$ Subclassifying stroke further could help clarifying which etiologies of stroke are affected by Hcy, and which patients could potentially benefit from Hcy-lowering treatment. As such, the clinical relevance of assessing Hcy in stroke patients or screening for hyperhomocysteinemia to prevent stroke remains undetermined. Taken together with the conflicting results on the effect of Hcy-lowering vitamin treatment, this may also explain why measuring plasma Hcy is not recommended in most clinical guidelines on ischemic stroke. $^{11-14}$

The most recent review of the literature found a $59 \%$ increased risk of stroke when Hcy increased $5 \mu \mathrm{mol} / \mathrm{L}{ }^{15} \mathrm{We}$ report a similar increased risk of $43 \%$ (95\% CI: $1.28-1.61)$ when standardizing reported ORs and using the same Hcy increments of $5 \mu \mathrm{mol} / \mathrm{L}^{18-23}$

The studies included in the present review assumed a linear association between Hcy levels and ischemic stroke; however, without describing this further or commenting on the hidden assumption of a linear association. As we observed a clear elevation in risk when surpassing $15 \mu \mathrm{mol} / \mathrm{L}$, our results question this assumption of a linear association.
Additionally, several studies performed a logarithmic transformation of Hcy levels prior to statistical analysis, indicating that they initially observed a nonlinear association with ischemic stroke risk, but without exploring this further.

To assess publication bias, we performed a funnel plot of our meta-analysis (-Fig. 3). Generally, at least 10 studies with varying sample sizes should be included for the test to have the power to distinguish chance from true asymmetry. Even though only six studies were included in the metaanalysis, we included the funnel plot as it was severely asymmetric. This could indicate publication bias, but it

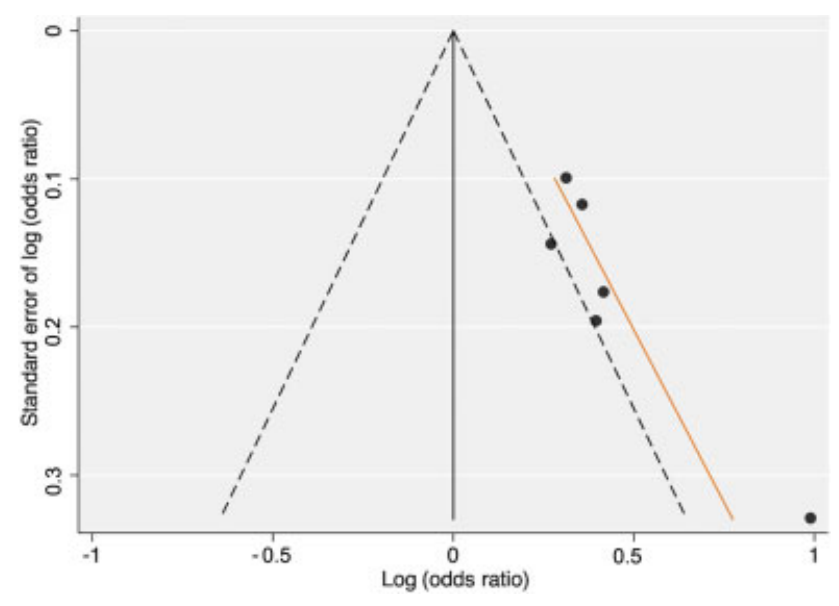

Fig. 3 Funnel plot of studies included in meta-analysis investigating the risk of ischemic stroke per $5 \mu \mathrm{mol} / \mathrm{L}$ increase in homocysteine. 
may also result from an overestimation of the effect of Hcy because of small study populations. ${ }^{123}$

Several large randomized controlled trials of Hcy-lowering treatment report mainly no effect on risk of CVD. ${ }^{12-14,124}$ These studies were excluded in the inclusion process of this review, as Hcy levels were not reported in the studies.

\section{Strengths and Limitations}

One of the strengths of the present systematic review was the strict requirement of outcome definition required for inclusion. Numerous studies investigating the relationship between Hcy and stroke do not differentiate between hemorrhagic or ischemic stroke in their outcome variable which could lead to a reduction of estimates toward the null. ${ }^{10,125,126}$ Second, this review only included multivariable adjusted risk estimates.

Some limitations have to be considered as well. First, statistical analyses were not standardized across studies and a meta-analysis of the dose-response relationship was only based on six studies. Second, the strategies for choosing control groups varied between hospital- and community-based controls; this could lead some studies to include a healthier control group compared with others. Third, we were not able to take into account differences in laboratory methods for measuring Hcy levels, and in turn, differences in reference intervals between studies. Forth, Hcy levels are influenced by a vast array of environmental and genetic factors, but most studies only adjusted effect measures for the main known cardiovascular risk factors, age, sex, hypertension, diabetes, cholesterol, smoking status, and BMI. However, six studies adjusted for renal function $23,106,109,113,115,117$ and additional nutritional factors, such as folate and vitamin B12 levels, were adjusted in six studies..$^{21-23,106,108,109}$ We were not able to further assess the possible differential impact of the etiology of elevated Hcy levels and the association with ischemic stroke. Furthermore, lipid-lowering medication, such as fibrates, commonly prescribed for patients in risk of CVD, might influence the Hcy levels. ${ }^{127}$ Any potential influence of lipid-lowering drugs on the association between Hcy and ischemic stroke was not assessed.

\section{Conclusion}

The present review and meta-analysis indicate that a nonlinear association could exist between Hcy levels and the risk of ischemic stroke. This implies that the risk of ischemic stroke increases when Hcy exceeds a certain level. Identifying this cut-off point would be of strong clinical interest, as it could help distinguish which patients could benefit of Hcylowering treatment.

\section{Funding}

This study was supported by grants from Redordati Rare Diseases. The funders of the study had no role in study design, data collection, data analysis, data interpretation, or manuscript preparation.

\section{Conflict of Interest}

M.H. has no conflicts of interest. A.M.H. has no conflicts of interest regarding the present paper but has the following general conflicts for interest: has received speaker's fees from CSL Behring, Bayer, Boehringer-Ingelheim, BristolMyers Squibb, and Astellas, and unrestricted research support from Octapharma and CSL Behring.

J.F.H.A. has no conflicts of interest regarding the present paper but has the following conflicts of interest outside the present work: received a speaker's fee within the last 36 months from Siemens Healthineers, Denmark, and a speaker's fee within the last 36 months from Teva Denmark A/S.

\section{References}

1 McCully KS. Atherogenesis and the chemical pathology of homocysteine. European Journal of Laboratory Medicine 1996; 4:121-128

2 Welch GN, Loscalzo J. Homocysteine and atherothrombosis. N Engl J Med 1998;338(15):1042-1050

3 Ansari R, Mahta A, Mallack E, Luo JJ. Hyperhomocysteinemia and neurologic disorders: a review. J Clin Neurol 2014;10(04): 281-288

4 Refsum H, Ueland PM, Nygård O, Vollset SE. Homocysteine and cardiovascular disease. Annu Rev Med 1998;49:31-62

5 Faraci FM, Lentz SR. Hyperhomocysteinemia, oxidative stress, and cerebral vascular dysfunction. Stroke 2004;35(02):345-347

6 Ungvari Z, Csiszar A, Edwards JG, et al. Increased superoxide production in coronary arteries in hyperhomocysteinemia: role of tumor necrosis factor-alpha, $\mathrm{NAD}(\mathrm{P}) \mathrm{H}$ oxidase, and inducible nitric oxide synthase. Arterioscler Thromb Vasc Biol 2003;23 (03):418-424

7 Eberhardt RT, Forgione MA, Cap A, et al. Endothelial dysfunction in a murine model of mild hyperhomocyst(e)inemia. J Clin Invest 2000;106(04):483-491

8 Hankey GJ, Eikelboom JW. Homocysteine and vascular disease. Lancet 1999;354(9176):407-413

9 Verhoef P, Hennekens CH, Malinow MR, Kok FJ, Willett WC, Stampfer MJ. A prospective study of plasma homocyst(e)ine and risk of ischemic stroke. Stroke 1994;25(10):1924-1930

10 Alfthan G, Pekkanen J, Jauhiainen M, et al. Relation of serum homocysteine and lipoprotein(a) concentrations to atherosclerotic disease in a prospective Finnish population based study. Atherosclerosis 1994;106(01):9-19

11 Ebbing M, Bønaa KH, Arnesen E, et al. Combined analyses and extended follow-up of two randomized controlled homocysteine-lowering B-vitamin trials. J Intern Med 2010;268(04): 367-382

12 Toole JF, Malinow MR, Chambless LE, et al. Lowering homocysteine in patients with ischemic stroke to prevent recurrent stroke, myocardial infarction, and death: the Vitamin Intervention for Stroke Prevention (VISP) randomized controlled trial. JAMA 2004;291(05):565-575

13 Huo Y, Li J, Qin X, et al; CSPPT Investigators. Efficacy of folic acid therapy in primary prevention of stroke among adults with hypertension in China: the CSPPT randomized clinical trial. JAMA 2015;313(13):1325-1335

14 Martí-Carvajal AJ, Solà I, Lathyris D, Dayer M. Homocysteinelowering interventions for preventing cardiovascular events. Cochrane Database Syst Rev 2017;8:CD006612

15 Wald DS, Law M, Morris JK. Homocysteine and cardiovascular disease: evidence on causality from a meta-analysis. BMJ 2002; 325(7374): 1202 
16 Moher D, Liberati A, Tetzlaff J, Altman DGPRISMA Group. Preferred reporting items for systematic reviews and meta-analyses: the PRISMA statement. BMJ 2009;339:b2535

17 National Heart Lung. and Blood InstituteStudy quality assessment tools. Accessed September 6, 2021 at: https://www.nhlbi. nih.gov/health-topics/study-quality-assessment-tools

18 Iso $\mathrm{H}$, Moriyama $\mathrm{Y}$, Sato S, et al. Serum total homocysteine concentrations and risk of stroke and its subtypes in Japanese. Circulation 2004;109(22):2766-2772

19 Cui R, Moriyama Y, Koike KA, et al; JACC Study group. Serum total homocysteine concentrations and risk of mortality from stroke and coronary heart disease in Japanese: the JACC study. Atherosclerosis 2008;198(02):412-418

20 Haltmayer $M$, Mueller T, Lange $\mathrm{W}$, et al. Relation between homocysteine and non-fatal stroke in peripheral arterial disease. Eur J Neurol 2002;9(06):609-614

21 Fallon UB, Virtamo J, Young I, et al. Homocysteine and cerebral infarction in finnish male smokers. Stroke 2003;34(06): 1359-1363

22 Loffredo L, Violi F, Fimognari FL, et al. The association between hyperhomocysteinemia and ischemic stroke in patients with non-valvular atrial fibrillation. Haematologica 2005;90(09): 1205-1211

23 Eikelboom JW, Hankey GJ, Anand SS, Lofthouse E, Staples N, Baker RI. Association between high homocyst(e)ine and ischemic stroke due to large- and small-artery disease but not other etiologic subtypes of ischemic stroke. Stroke 2000;31(05): 1069-1075

24 Atanassova PA, Angelova E, Tzvetanov P, Semerdjieva M, Dimitrov BD. Modelling of increased homocysteine in ischaemic stroke: post-hoc cross-sectional matched case-control analysis in young patients. Arq Neuropsiquiatr 2007;65(01):24-31

25 Bosco P, Guéant-Rodriguez RM, Anello G, et al. Association of homocysteine (but not of MTHFR $677 \mathrm{C}>\mathrm{T}$, MTR $2756 \mathrm{~A}>\mathrm{G}$, MTRR $66 \mathrm{~A}>\mathrm{G}$ and TCN2 $776 \mathrm{C}>\mathrm{G}$ ) with ischaemic cerebrovascular disease in Sicily. Thromb Haemost 2006;96(02): 154-159

26 Delport R, Ubbink JB, Vermaak WJ, Rossouw H, Becker PJ, Joubert J. Hyperhomocysteinaemia in black patients with cerebral thrombosis. QJM 1997;90(10):635-639

27 Haapaniemi E, Helenius J, Soinne L, Syrjälä M, Kaste M, Tatlisumak T. Serial measurements of plasma homocysteine levels in early and late phases of ischemic stroke. Eur J Neurol 2007;14 (01):12-17

28 Hassan A, Hunt BJ, O'Sullivan M, et al. Homocysteine is a risk factor for cerebral small vessel disease, acting via endothelial dysfunction. Brain 2004;127(pt. 1):212-219

29 Kara N, Senes M, Coskun O, Inan L, Saydam G, Yucel D. Urinary methylmalonic acid levels in patients with acute ischemic stroke. Clin Biochem 2009;42(7,8):578-583

30 Kario K, Duell PB, Matsuo T, et al. High plasma homocyst(e)ine levels in elderly Japanese patients are associated with increased cardiovascular disease risk independently from markers of coagulation activation and endothelial cell damage. Atherosclerosis 2001;157(02):441-449

31 Kelly PJ, Kistler JP, Shih VE, et al. Inflammation, homocysteine, and vitamin B6 status after ischemic stroke. Stroke 2004;35(01): $12-15$

32 Kim MH, Moon JS, Park SY, et al. Different risk factor profiles between silent brain infarction and symptomatic lacunar infarction. Eur Neurol 2011;65(05):250-256

$33 \mathrm{Kim} \mathrm{OJ}$, Hong $\mathrm{SH}$, Oh SH, et al. Association between VEGF polymorphisms and homocysteine levels in patients with ischemic stroke and silent brain infarction. Stroke 2011;42(09): 2393-2402

34 Kristensen B, Malm J, Nilsson TK, et al. Hyperhomocysteinemia and hypofibrinolysis in young adults with ischemic stroke. Stroke 1999;30(05):974-980
35 Kucukarabaci B, Gunes HV, Ozdemir G, et al. Investigation of association between plasminogen activator inhibitor type-1 (PAI-1) gene 4G/5G polymorphism frequency and plasma PAI1 enzyme activity in patients with acute stroke. Genet Test 2008; 12(03):443-451

36 Lee JH, Kim OJ, Kim HS, et al. Polymorphisms of thymidylate synthase enhancer region (TSER) and upstream stimulatory factor 1 (USF1 306G > A) genes are associated with plasma homocysteine level and susceptibility to ischemic stroke in a Korean population. Genes Genomics 2008;30:563-570

37 Lehmann MF, Kallaur AP, Oliveira SR, et al. Inflammatory and metabolic markers and short-time outcome in patients with acute ischemic stroke in relation to TOAST subtypes. Metab Brain Dis 2015;30(06):1417-1428

38 Li G, Liu Y, Li X, et al. Association of pai- $14 \mathrm{~g} / 5 \mathrm{~g}$ polymorphism with ischemic stroke in Chinese patients with type 2 diabetes mellitus. Genet Test Mol Biomarkers 2018;22(09):554-560

39 Lindgren A, Brattström L, Norrving B, Hultberg B, Andersson A, Johansson BB. Plasma homocysteine in the acute and convalescent phases after stroke. Stroke 1995;26(05):795-800

40 Lu SJ, Zhou XS, Zheng Q Chen HL, Geng YL. Platelet membrane receptor $\mathrm{P} 2 \mathrm{Y} 12 \mathrm{H} 1 / \mathrm{H} 2$ polymorphism is highly associated with cerebral infarction: a case-control study. Neuropsychiatr Dis Treat 2018;14:2225-2231

41 Luo HC, Luo QS, Wang CF, Lei M, Li BL, Wei YS. Association of miR146a, miR-149, miR-196a2, miR-499 gene polymorphisms with ischemic stroke in a Chinese people. Oncotarget 2017;8(46): 81295-81304

42 Ma L, Jiang Y, Kong X, et al. Synergistic effect of the MTHFR C677t and EPHX2 G860A polymorphism on the increased risk of ischemic stroke in Chinese type 2 diabetic patients. J Diabetes Res 2017;2017:6216205

43 Ma SG, Xu W, Wei CL, et al. Role of ischemia-modified albumin and total homocysteine in estimating symptomatic lacunar infarction in type 2 diabetic patients. Clin Biochem 2011;44 (16):1299-1303

44 Mao X, Han L. The relationship of methylenetetrahydrofolate reductase gene C677T polymorphism and ischemic stroke in Chinese Han population. Ann Clin Lab Sci 2018;48(02):242-247

45 Meiklejohn DJ, Vickers MA, Dijkhuisen R, Greaves M. Plasma homocysteine concentrations in the acute and convalescent periods of atherothrombotic stroke. Stroke 2001;32(01):57-62

46 Mejia Mohamed EH, Tan KS, Ali JM, Mohamed Z. TT genotype of the methylenetetrahydrofolate reductase $\mathrm{C677T}$ polymorphism is an important determinant for homocysteine levels in multiethnic Malaysian ischaemic stroke patients. Ann Acad Med Singap 2011;40(04):186-191

47 Modi M, Prabhakar S, Majumdar S, Khullar M, Lal V, Das CP. Hyperhomocysteinemia as a risk factor for ischemic stroke: an Indian scenario. Neurol India 2005;53(03):297-301, discussion 301-302

48 Moe KT, Woon FP, De Silva DA, et al. Association of acute ischemic stroke with the MTHFR C677T polymorphism but not with NOS3 gene polymorphisms in a Singapore population. Eur J Neurol 2008;15(12):1309-1314

49 Mojiminiyi OA, Marouf R, Al Shayeb AR, et al. Determinants and associations of homocysteine and prothrombotic risk factors in Kuwaiti patients with cerebrovascular accident. Med Princ Pract 2008;17(02):136-142

50 Parnetti L, Caso V, Santucci A, et al. Mild hyperhomocysteinemia is a risk-factor in all etiological subtypes of stroke. Neurol Sci 2004;25(01):13-17

51 Perini F, Galloni E, Bolgan I, et al. Elevated plasma homocysteine in acute stroke was not associated with severity and outcome: stronger association with small artery disease. Neurol Sci 2005; 26(05):310-318

52 Pezzini A, Del Zotto E, Archetti S, et al. Plasma homocysteine concentration, C677T MTHFR genotype, and 844ins68bp CBS 
genotype in young adults with spontaneous cervical artery dissection and atherothrombotic stroke. Stroke 2002;33(03): 664-669

53 Press RD, Beamer N, Evans A, DeLoughery TG, Coull BM. Role of a common mutation in the homocysteine regulatory enzyme methylenetetrahydrofolate reductase in ischemic stroke. Diagn Mol Pathol 1999;8(01):54-58

54 Rahman A, Gupta RD, Quraishi FA, Saha UK, Miah MNA, Ali Z. Relationship between homocysteine and ischemic stroke. Journal of Medicine (Bangladesh) 2013;14:47-51

55 Tantirittisak T, Sura T, Moleerergpoom W, Hanchaipiboolkul S. Plasma homocysteine and ischemic stroke patients in Thailand. J Med Assoc Thai 2007;90(06):1183-1187

56 Ustundag M, Orak M, Guloglu C, Ozturk E, Tamam Y, Kale E. The role of serum ferritin, pro-brain natriuretic peptide and homocysteine levels in determining ischaemic stroke subtype, severity and mortality. Hong Kong J Emerg Med 2010;17:13-21

57 Vayá A, Ejarque I, Tembl J, Corella D, Laiz B. Hyperhomocysteinemia, obesity and cryptogenic stroke. Clin Hemorheol Microcirc 2011;47(01):53-58

58 Wang C, Han L, Wu Q et al. Association between homocysteine and incidence of ischemic stroke in subjects with essential hypertension: a matched case-control study. Clin Exp Hypertens 2015;37(07):557-562

59 Wang CY, Chen ZW, Zhang T, et al. Elevated plasma homocysteine level is associated with ischemic stroke in Chinese hypertensive patients. Eur J Intern Med 2014;25(06):538-544

60 Xia XS, Li X, Wang L, Wang JZ, Ma JP, Wu CJ. Supplementation of folic acid and vitamin $B_{12}$ reduces plasma levels of asymmetric dimethylarginine in patients with acute ischemic stroke. J Clin Neurosci 2014;21(09):1586-1590

61 Yadav BK, Yadav R, Chang H, et al. Genetic polymorphisms rs699947, rs1570360, and rs3025039 on the VEGF gene are correlated with extracranial internal carotid artery stenosis and ischemic stroke. Ann Clin Lab Sci 2017;47(02):144-155

62 Yang TH, Chang CY, Hu ML. Various forms of homocysteine and oxidative status in the plasma of ischemic-stroke patients as compared to healthy controls. Clin Biochem 2004;37(06): 494-499

63 Yang Z, Wang L, Zhang W, Wang X, Zhou S. Plasma homocysteine involved in methylation and expression of thrombomodulin in cerebral infarction. Biochem Biophys Res Commun 2016;473 (04):1218-1222

64 Yao Y, Gao LJ, Zhou Y, et al. Effect of advanced age on plasma homocysteine levels and its association with ischemic stroke in non-valvular atrial fibrillation. J Geriatr Cardiol 2017;14(12): 743-749

65 Yoo JH, Chung CS, Kang SS. Relation of plasma homocyst(e)ine to cerebral infarction and cerebral atherosclerosis. Stroke 1998;29 (12):2478-2483

66 Zhang F, Li X, Dong Q, Wang Y, Zhang H. Risk of acute cerebral infarction and plasma asymmetrical dimethylarginine and homocysteine levels: a clinical correlation analysis of Chinese population. J Stroke Cerebrovasc Dis 2014;23(09):2225-2232

67 Zhang H, Zhao X, Wang C, et al. A preliminary study of the association between apolipoprotein e promoter methylation and atherosclerotic cerebral infarction. J Stroke Cerebrovasc Dis 2019;28(04):1056-1061

68 Zhu F, Jin XP, Zhu M, et al. Matrix metalloproteinase 10 gene polymorphism and atherothrombotic cerebral infarction risk in a Han Chinese population. Int J Clin Exp Med 2013;6(07): 567-575

69 Adunsky A, Weitzman A, Fleissig Y, et al. The relation of plasma total homocysteine levels to prevalent cardiovascular disease in older patients with ischemic stroke. Aging (Milano) 2000;12 (01):48-52

70 Akpalu A, Nyame P. Plasma homocysteine as a risk factor for strokes in ghanaian adults. Ghana Med J 2009;43(04):157-163
71 Al-Allawi NA, Avo AS, Jubrael JM. Methylenetetrahydrofolate reductase C677T polymorphism in Iraqi patients with ischemic stroke. Neurol India 2009;57(05):631-635

72 Araki A, Sako Y, Fukushima Y, Matsumoto M, Asada T, Kita T. Plasma sulfhydryl-containing amino acids in patients with cerebral infarction and in hypertensive subjects. Atherosclerosis 1989;79(2,3):139-146

73 Salem-Berrabah OB, Mrissa R, Machghoul S, et al. Hyperhomocysteinemia, C677T MTHFR polymorphism and ischemic stroke in Tunisian patients. Tunis Med 2010;88(09):655-659

74 Brattström L, Lindgren A, Israelsson B, et al. Hyperhomocysteinaemia in stroke: prevalence, cause, and relationships to type of stroke and stroke risk factors. Eur J Clin Invest 1992;22(03): 214-221

75 Celikbilek A, Ismailogullari S, Zararsiz G. Neutrophil to lymphocyte ratio predicts poor prognosis in ischemic cerebrovascular disease. J Clin Lab Anal 2014;28(01):27-31

76 Cingozbay BY, Yiginer O, Cebeci BS, Kardesoglu E, Demiralp E, Dincturk M. Role of homocysteine for thromboembolic complication in patients with non-valvular atrial fibrilation. Blood Coagul Fibrinolysis 2002;13(07):609-613

77 Coull BM, Malinow MR, Beamer N, Sexton G, Nordt F, de Garmo P. Elevated plasma homocyst(e)ine concentration as a possible independent risk factor for stroke. Stroke 1990;21(04): 572-576

78 El Kossi MM, Zakhary MM. Oxidative stress in the context of acute cerebrovascular stroke. Stroke 2000;31(08):1889-1892

79 Fatima S, Memon SF, Ansari AK, Baloch AH. Hyperhomocystenemia as a risk factor for ischemic stroke. J Liaquat Uni Med Health Sci 2012;11:158-161

80 Fekih-Mrissa N, Mrad M, Klai S, et al. Methylenetetrahydrofolate reductase (C677T and A1298C) polymorphisms, hyperhomocysteinemia, and ischemic stroke in Tunisian patients. J Stroke Cerebrovasc Dis 2013;22(04):465-469

81 Karakurum Goksel B, Karatas M, Nebioglu A, et al. Subclinical hypothyroidism, hyperhomocysteinemia and dyslipidemia: investigating links with ischemic stroke in Turkish patients. Neurol Res 2007;29(08):871-876

82 Han SC, Guo Y, Sun GJ, Gu YY. Relation of plasma homocysteine with folic acid and vitamine b12 in patients with cerebral infarction. Zhongguo Linchuang Kangfu 2002;6:2970-2971

83 Karabulut KU, Bayir A, Kara F, Ak A. The levels of serum b12, folic acid and homocysteine in the thromboembolic diseases. J Clin Anal Med 2017;8:130-133

84 Kokocińska D, Cierpka L, Chmiel B, et al. The usefulness of assessing the serum levels of homocysteine in diagnosis of atherosclerosis. Acta Angiologica 2005;11:114-120

85 Li FS, Luo XW, Jia LH, et al. Relativity of the type and grade of stroke with the serum homocysteine level. Zhongguo Linchuang Kangfu 2004;8:1974-1975

86 Liu JG, Zhang ZC, Gao HF, Liu HX, Tan XM. Relationship between hyperhomocysteinemia and cerebral stroke in young and middle-aged people. Zhongguo Linchuang Kangfu 2005; 9:221-223

87 Moghaddasi M, Mamarabadi M, Mirzadeh S, Freydoonnejad AA, Razjouyan H. Homocysteine, vitamin B12 and folate levels in Iranian patients with ischemic stroke. Neurol Res 2010;32(09): 953-956

88 Mykhalojko OJ, Mykhalojko IJ. Some biochemical changes in patients with acute ischemic stroke. Ukr Biochem J 2017; 89:31-35

89 Narang AP, Verma I, Kaur S, Narang A, Gupta S, Avasthi G. Homocysteine-risk factor for ischemic stroke? Indian J Physiol Pharmacol 2009;53(01):34-38

90 Omrani HQ, Shandiz EE, Qabai M, Chaman R, Fard HA, Qaffarpoor M. Hyperhomocysteinemia, folateo and B12 vitamin in Iranian patients with acute ischemic stroke. ARYA Atheroscler 2011;7 (03):97-101 
91 Peng H, Huang Q Li Y, et al. Study on the relationship between plasma homocysteine and acute cerebral vascular disease. J Tongji Med Univ 2000;20(04):330-331

92 Sawuła W, Banecka-Majkutewicz Z, Kadziński L, et al. Homocysteine level and metabolism in ischemic stroke in the population of Northern Poland. Clin Biochem 2009;42(06):442-447

93 Sönmezler A, Ulaş T, Dal MS, Demir ME, Karababa IF, Büyükhatipo[lu H. Plasma homocysteine levels in patients with acute ischemic stroke: A cross-sectional study. Turkiye Klinikleri Journal of Medical Sciences 2013;33:384-388

94 Sun JZ, Xu Y, Lu H, Zhu Y. Polymorphism of the methylenetetrahydrofolate reductase gene association with homocysteine and ischemic stroke in type 2 diabetes. Neurol India 2009;57 (05):589-593

95 Sun WP, Zhao JX, Wan Q, Wei D, Yu YX. Association of hyperhomocysteinemia and methylenetetrahydrofolate reductase gene polymorphisms with ischemic stroke in northwest Chinese population. Zhongguo Linchuang Kangfu 2005;9:171-173

96 Tas A, Tas F, Candan F, Topaktas S. Association between homocysteine level and intima-media thickness in patients with first ischemic stroke. Neurol Psychiatry Brain Res 2005;12:53-58

97 Unal E, Mungan S, Bilen S, et al. The effects of lipoprotein(a) and homocysteine on prognosis and risk factors in acute ischemic stroke. Int J Neurosci 2013;123(08):532-536

98 Urbańska EM, Luchowski P, Luchowska E, et al. Serum kynurenic acid positively correlates with cardiovascular disease risk factor, homocysteine: a study in stroke patients. Pharmacol Rep 2006; 58(04):507-511

99 Wei W, Chen X, Lin X, et al. Serum PPARY level and PPARY gene polymorphism as well as severity and prognosis of brain injury in patients with arteriosclotic cerebral infarction. Exp Ther Med 2018;16(05):4058-4062

$100 \mathrm{Wu}$ GH, Kong FZ, Dong XF, et al. Association between hyperhomocysteinemia and stroke with atherosclerosis and small artery occlusion depends on homocysteine metabolism-related vitamin levels in Chinese patients with normal renal function. Metab Brain Dis 2017;32(03):859-865

101 Yi L, Huang Y, Wu T, Wu J. A magnetic nanoparticles-based method for DNA extraction from the saliva of stroke patients. Neural Regen Res 2013;8(32):3036-3046

102 Yingdong Z, Zhigang Z, Yang L. Association of plasma homocysteine level and N5,N10-methylenetetrahydrofolate reductase gene polymorphism with cerebral infarction. Chin Med Sci J 2002;17(04):231-235

103 Zhang W, Zhang X. Correlation between the youth cerebral infarction in different TOAST classifications and high homocysteine. Cell Biochem Biophys 2015;71(01):39-42

104 Zhou J, Zhang SZ, Zhang Y, Chen Z, Ding MP. Relationship between plasma homocysteine level and stroke. Zhongguo Linchuang Kangfu 2005;9:181-183

105 Tanne D, Haim M, Goldbourt U, et al. Prospective study of serum homocysteine and risk of ischemic stroke among patients with preexisting coronary heart disease. Stroke 2003;34(03): 632-636

106 Shimizu H, Kiyohara Y, Kato I, et al. Plasma homocyst(e)ine concentrations and the risk of subtypes of cerebral infarction. The Hisayama study. Cerebrovasc Dis 2002;13(01):9-15

107 Tascilar N, Ekem S, Aciman E, et al. Hyperhomocysteinemia as an independent risk factor for cardioembolic stroke in the Turkish population. Tohoku J Exp Med 2009;218(04):293-300

108 Tan NC, Venketasubramanian N, Saw SM, Tjia HT. Hyperhomocyst(e)inemia and risk of ischemic stroke among young Asian adults. Stroke 2002;33(08):1956-1962

109 Khan U, Crossley C, Kalra L, et al. Homocysteine and its relationship to stroke subtypes in a UK black population: the south London ethnicity and stroke study. Stroke 2008;39(11): 2943-2949
110 Campbell DJ, Woodward M, Chalmers JP, et al. Soluble vascular cell adhesion molecule 1 and $\mathrm{N}$-terminal pro-B-type natriuretic peptide in predicting ischemic stroke in patients with cerebrovascular disease. Arch Neurol 2006;63(01):60-65

111 Hultdin J, Van Guelpen B, Winkvist A, et al. Prospective study of first stroke in relation to plasma homocysteine and MTHFR $677 \mathrm{C}>\mathrm{T}$ and $1298 \mathrm{~A}>\mathrm{C}$ genotypes and haplotypes - evidence for an association with hemorrhagic stroke. Clin Chem Lab Med 2011;49(09):1555-1562

112 Kaplan RC, McGinn AP, Baird AE, et al. Inflammation and hemostasis biomarkers for predicting stroke in postmenopausal women: the Women's Health Initiative Observational Study. J Stroke Cerebrovasc Dis 2008;17(06):344-355

113 Rueda-Clausen CF, Córdoba-Porras A, Bedoya G, et al. Increased plasma levels of total homocysteine but not asymmetric dimethylarginine in Hispanic subjects with ischemic stroke FREC-VI sub-study. Eur J Neurol 2012;19(03):417-425

114 Liang Y, Chen P, Sun Y, Feng P, Huang B, Jiang T. Evaluation of laboratory parameters in predicting ischemic stroke in essential hypertension patients. Biomedical Research (India) 2017; 28:4013-4019

115 Li Z, Sun L, Zhang H, et al; Multicenter Case-Control Study in China. Elevated plasma homocysteine was associated with hemorrhagic and ischemic stroke, but methylenetetrahydrofolate reductase gene C677T polymorphism was a risk factor for thrombotic stroke: a Multicenter Case-Control Study in China. Stroke 2003;34(09):2085-2090

116 Shi Z, Liu S, Guan Y, et al. Changes in total homocysteine levels after acute stroke and recurrence of stroke. Sci Rep 2018;8(01): 6993

117 Petri M, Roubenoff R, Dallal GE, Nadeau MR, Selhub J, Rosenberg IH. Plasma homocysteine as a risk factor for atherothrombotic events in systemic lupus erythematosus. Lancet 1996;348 (9035):1120-1124

118 Bostom AG, Rosenberg IH, Silbershatz H, et al. Nonfasting plasma total homocysteine levels and stroke incidence in elderly persons: the Framingham Study. Ann Intern Med 1999;131(05): 352-355

119 Zee RY, Mora S, Cheng S, et al. Homocysteine, 5,10-methylenetetrahydrofolate reductase $677 \mathrm{C}>\mathrm{T}$ polymorphism, nutrient intake, and incident cardiovascular disease in 24,968 initially healthy women. Clin Chem 2007;53(05):845-851

120 Schindler K, Zauner C, Buchmayer H, et al. High prevalence of hyperhomocysteinemia in critically ill patients. Crit Care Med 2000;28(04):991-995

121 Lonn E, Held C, Arnold JM, et al; HOPE-2 Investigators. Rationale, design and baseline characteristics of a large, simple, randomized trial of combined folic acid and vitamins B6 and B12 in highrisk patients: the Heart Outcomes Prevention Evaluation (HOPE)-2 trial. Can J Cardiol 2006;22(01):47-53

122 Spence JD. Homocysteine-lowering therapy: a role in stroke prevention? Lancet Neurol 2007;6(09):830-838

123 Sterne JA, Sutton AJ, Ioannidis JP, et al. Recommendations for examining and interpreting funnel plot asymmetry in metaanalyses of randomised controlled trials. BMJ 2011;343:d4002

124 Kong X, Huang X, Zhao M, et al. Platelet count affects efficacy of folic acid in preventing first stroke. J Am Coll Cardiol 2018;71 (19):2136-2146

125 Perry IJ, Refsum H, Morris RW, Ebrahim SB, Ueland PM, Shaper AG. Prospective study of serum total homocysteine concentration and risk of stroke in middle-aged British men. Lancet 1995; 346(8987):1395-1398

126 Stehouwer CD, Weijenberg MP, van den Berg M, Jakobs C, Feskens EJ, Kromhout D. Serum homocysteine and risk of coronary heart disease and cerebrovascular disease in elderly men: a 10-year follow-up. Arterioscler Thromb Vasc Biol 1998;18(12): 1895-1901 
127 Sahebkar A, Pirro M, Reiner Ž, et al. A systematic review and meta-analysis of controlled trials on the effects of statin and fibrate therapies on plasma homocysteine levels. Curr Med Chem 2016;23(39):4490-4503

128 Cao L, Guo Y, Zhu Z. Study of the inflammatory mechanisms in hyperhomocysteinemia on large-artery atherosclerosis based on hypersensitive c-reactive protein-a study from southern china. J Stroke Cerebrovasc Dis 2019;28(07):1816-1823

129 Dai Z, Jiao Y, Fan Q, Qi A, Xiao L, Li J. Homocysteine, interleukin$1 \beta$, and fasting blood glucose levels as prognostic markers for diabetes mellitus complicated with cerebral infarction and correlated with carotid intima-media thickness. Exp Ther Med 2020;19(02):1167-1174

130 Wei GJ, Yuan MQ Jiang LH, et al. A genetic variant of mir-34a contributes to susceptibility of ischemic stroke among Chinese population. Front Physiol 2019;10:432

131 Alkali NH, Watt H, Bwala SA, Gadzama A. Association of plasma homocysteine and ischaemic stroke in a nigerian population. Pakistan J Med Sci 2006;22:405-408 